\title{
THE OUTCOME OF DOUBLE DARTOS VERSUS SINGLE LAYER FLAP IN SNODGRASS URETHROPLASTY FOR DISTAL HYPOSPA- DIAS REPAIR IN BASRA TRAINING CENTER OF UROLOGY
}

\author{
Murtadha Almusafer *, Safaa Gatea Mezban @, Murtada Faisal \# \\ *Professor of Urology, University of Basrah-College of Medicine, @ Urology department of Al-Sadder Teaching Hospital, \\ \# Urology department of Al-Mawani' Hospital
}

\begin{abstract}
Hypospadias, a nomination of medical term which was derived from the Greek terms: hypo (under) and spadon (rent, fissure). It is one of the congenital abnormalities of the genitourinary tract. There are about 400 different procedures described for correction of this type of anomaly, but Tubularized Incised Plate (TIP) Urethroplasty is considered the most popular one, and there are multiple variations in this procedure to get high success rate and decrease the complications. In this study, we compare between single layer dartos flap versus double layer dorsal flaps in TIP urethroplasty.

This is to assess the outcomes of double dartos flaps versus single layer flap in TIP urethroplasty for primary distal hypospadias repair in Basrah Teaching Center regarding the success rate, and to investigate the importance of double flaps in preventing possible complications in particular, urethral fistula.

A cross sectional prospective study was done in Basra Teaching Hospital, between January 2018 to March 2020. A total of 50 boys, 2 to 10 year- old with coronal and sub coronal primary Hypospadias were treated with TIP urethroplasty (Snodgrass procedure) by one surgical team, who were referred to Basrah Teaching Hospital from private and outpatient clinics. Patients were divided into 2 groups: (group I: 25 patients) single layer Dartos flap \& (group II: 25 patients) double layers of Dartos flaps. Six patients were missing during follow up, coincidentally 3 patients in each group. The mean age was 4.55 and 4.86 year for groups I, II respectively, the mean operative time was 88.81 and 91.86 minutes for group I \& group II respectively. The success rate was $(81 \%)$ and $(86 \%)$ for group I, II respectively, with exception of complications which need re-do surgery. Urethrocutaneous fistula (UF) was developed in $(22.7 \%)$ in group I, and in (4.5\%) in group II. Bleeding was happened in 2 cases $(9.1 \%)$ in group I and 3 cases $(13.6 \%)$ in group II. Meatal stenosis was diagnosed in $(9.1 \%)$ in group I and (13.6\%) in group II. Glans dehiscence was seen in 1 case (4.5\%) for each group. There was a significant difference between the two groups in the occurrence of UF $(P=0.001)$.

According to our evidence in this study, double dartos flaps is easy to be harvested, safe procedure, and represents very good choice for UF prevention. Although the number of complicated patients regarding bleeding and meatal stenosis are higher in group II than group I but they were statistically insignificant.
\end{abstract}

Keywords: Hypospadias, Urethroplasty, Tubularized Incised Plate (TIP), urethral fistula, dartos flaps.

\section{Introduction}

Typospadias, a nomination of medical term 1 which was derived from the Greek terms: hypo (under) and spadon (rent, fissure). It is one of the congenital abnormalities of the genitourinary tract ${ }^{1}$. Many publications discussing this anomaly are recorded annually. There are about 400 different procedures described for correction of this type of anomaly, but TIP urethroplasty is considered the most popular one ${ }^{2}$.

hypospadias is associated with three penile anomalies:

(1) Ventrally located urethral meatus anywhere between the glans penis and the perineum.
(2) penile ventral curvature (chordee).

(3) Dorsally hooded prepucial skin in association with a ventral deficiency.

The second and third penile findings are not mandatory for the diagnosis of hypospadias ${ }^{3,4}$.

Many and different classifications of hypospadias have been defined and published ${ }^{5}$.

Hypospadias is generally classified according to the anatomical position of the ventral urethral meatus:

(1) Distal hypospadias $70-80 \%$.

(2) Mid - shaft hypospadias $15-20 \%$.

(3) Proximal hypospadias 5\% 6 . 


\section{Aim of study}

To assess the outcome of double dartos flap (DDF) versus single layer flap in TIP urethroplasty (Snodgrass procedure) for primary distal hypospadias repair in Basrah Teaching Center with regard to success rate, and to investigate the importance of double flaps in preventing possible complications in particular, urethral fistula.

\section{Patients \& Methods}

Study Design: A cross sectional prospective study was done in Basrah Teaching Hospital (urological department) between January 2018 to March 2020.

Patients selection: A total of 50 boys, 2 to 10 years old with coronal and sub coronal primary Hypospadias were treated with TIP urethroplasty (Snodgrass technique) by one surgeon, who were referred to Basrah Teaching Hospital from private and outpatient clinics, patients were divided into 2 groups:

- (group I: 25 patients) single layer Dartos flap. - (group II: 25 patients) double layers of Dartos flaps to cover the reconstructed site of neourethra.

Six patients were missing during follow up, coincidentally 3 patients in each group. The parents were informed about the general aspects of the surgery including risks and complications, the parents then signed an informed consent form.

A full medical and surgical history were recorded; clinical examination was performed. Investigations include (renal function tests, urinalysis, new imaging including ultrasonography of urinary system was optional done accordingly, urine culture and sensitivity if positive urinalysis was detected, in addition to the routine preoperative investigations, were performed), pre-operative antibiotics were given in selected cases (patients with a history of infection e.g.: UTI, tonsillitis) with completion the duration of follow up starting at 1,3 , and 6 months.

Inclusion criteria: Patients with coronal and sub coronal distal primary penile hypospadias who are candidates for Snodgrass TIP urethroplasty.

Exclusion criteria: Include, history of failed urethroplasty, history of circumcision, severe penile curvature which might need urethral plate excision for correction.

Surgical steps: After placing traction suture through the glans, a circumferential subglandular skin incision was carried out around dorsally, complete degloving done, any ventral curvature if present, was corrected. The mid line incision was made through urethral plate, two parallel incisions were done along the junction of glans wings to the urethral plate, and the glans wings were elevated laterally, then suitable silicone urethral catheter was passed into the bladder, the urethral plate is tubularized by subcuticular closures of $5 / 0$ vicryl suture.

\section{Monolayer Dartos flap Coverage (group I)}

A suitable dartos flap was harvested and rotated ventrally to cover the front of the neourethra, and fixed to the contralateral fascial layers and glandular tissue beneath the glans wings using superficial 5/0 Vicryl stitches.

\section{Double-Layer Dartos flaps Coverage (group II)}

A vascularized dartos flap was dissected from the dorsal preputial and shaft skin, wider flap bisectioned in the midline to form two well-vascularized rectangular wings, the right wing was rotated laterally from the right side to cover the neourethra, It was stitched to the periurethral tissue using 5/0 vicryl sutures. The left wing was then rotated laterally from the left side to overlap the right wing, it was sutured to the periurethral tissue and to the external surface of the right dartos wing using the same suture material, the glans wings closures were completed by $5 / 0$ mattress sutures over the overlapped double dartos covering flaps, dorsal penile skin was bisectioned in midline to cover the ventral defect so that the final appearance look like the circumcision.

A dressing was placed postoperatively for (3- 7) days for good hemostasis. Trimethoprim-sulfamethoxazole either (co-trimoxazole $240 \mathrm{mg} / 5 \mathrm{~mL}$ ) BID or (co-trimoxazole $480 \mathrm{mg}$ tablet) BID, was given as a post-operative antibiotic for six days. Ibuprofen (40 mg/kg TDS), was prescribed as an oral analgesic agent.

Most of the patients were discharged from hospital after (1-2) days, whereas others stayed beyond $48 \mathrm{~h}$ due to postoperative complications. Catheters were removed at postoperative day 7 . Children were followed for a period of 6 months.

Statistical analysis: The data had been calculated by using (SPSSTM version 24) SOFTWARE.

$P$ values were estimated and considered statistically significant at $\mathrm{P}<0.05$. Statistical analysis and comparisons between the groups were done using the chi-square test. 


\section{Results}

This study included a total of 50 patients, divided randomly by even and odd system into 2 groups:

- Group I: 25 patients with single layer repair with odd numbers.

- Group II: 25 patients with double layer repair with even numbers.

Six patients were missed during follow up, coincidentally 3 patients for each group. So, 44 patients have been included in the statistics calculations. The mean age was 4.55 and 4.86 year for groups I, II respectively, both groups were comparable in terms of meatal location, group I had 8 cases coronal and 14 cases sub coronal, group II had 10 and 12 cases for coronal and sub coronal respectively, the mean operative time was 88.81 and $91.86 \mathrm{~min}-$ utes for group I \& group II respectively, table 1.

Table 1: Demographic distribution data of the involved patients.

\begin{tabular}{|c|c|c|c|c|}
\hline & & & Group1 & Group2 \\
\hline \multirow{3}{*}{\multicolumn{2}{|c|}{ Age }} & Mean & 4.559 & 4.868 \\
\hline & & $\mathrm{SD}^{*}$ & 2.0234 & 2.2531 \\
\hline & & SD*. Error Mean & 0.4314 & 0.4804 \\
\hline \multirow{6}{*}{ Age groups } & \multirow{2}{*}{$2-5 \mathrm{yrs}$} & Count & 14 & 12 \\
\hline & & $\%$ within Groups & $63.60 \%$ & $54.50 \%$ \\
\hline & \multirow{2}{*}{$6-8 \mathrm{yrs}$} & Count & 7 & 8 \\
\hline & & $\%$ within Groups & $31.80 \%$ & $36.40 \%$ \\
\hline & \multirow{2}{*}{$9-10$ yrs } & Count & 1 & 2 \\
\hline & & $\%$ within Groups & $4.50 \%$ & $9.10 \%$ \\
\hline \multirow{4}{*}{ Type } & \multirow{2}{*}{ Coronal } & Count & 8 & 10 \\
\hline & & $\%$ within Groups & $36.40 \%$ & $45.50 \%$ \\
\hline & \multirow{2}{*}{ sub-coronal } & Count & 14 & 12 \\
\hline & & $\%$ within Groups & $63.60 \%$ & $54.50 \%$ \\
\hline \multirow{3}{*}{\multicolumn{2}{|c|}{ Operative time in minutes }} & Mean & 88.8182 & 91.8636 \\
\hline & & $\mathrm{SD}^{*}$ & 6.46335 & 6.46084 \\
\hline & & SD*. Error Mean & 1.37799 & 1.37746 \\
\hline
\end{tabular}

*Standard deviation

The success rate was dependent on cosmetical, functional acceptance and complications that have been treated by conservative measures, it was
$(81 \%)$ and $(86 \%)$ for group I, II respectively, with exception of complications which need redo surgery, table 2 .

Table 2: Success rate for each group.

\begin{tabular}{||c|c|c|c||}
\hline & Total No & No of success cases & Success rate $\%$ \\
\hline Group 1 & 22 & 18 & $81 \%$ \\
\hline Group 2 & 22 & 19 & $86 \%$ \\
\hline
\end{tabular}


Urethrocutaneous fistula (UF) was developed in 5 patients $(22.7 \%)$ in group I, the fistula was small and 3 cases treated by surgical intervention, and 2 cases was treated conservatively and healed spontaneously, UF was developed in 1 patient $(4.5 \%)$ in group II, the fistula was happened in same patient who suffered from surgical site infection postoperative and treated with continued antibiotics for 2 weeks and change dressing daily, the fistula was treated by surgical intervention. Bleeding was happened in 5 cases $(11.4 \%)$ for both groups, 2 cases $(9.1 \%)$ in group I and 3 cases $(13.6 \%)$ in group II, all cases was treated conservatively with tight dressing except one case in group II was treated by surgical exploration. Meatal stenosis was diagnosed in 2 patients $(9.1 \%)$ in group I and 3 patients $(13.6 \%)$ in group II, all cases in both groups were treated conservatively by frequent dilatation, glans dehiscence was seen in 1 case $(4.5 \%)$ for each group, the management for both groups was redo surgery.

The differences between the two groups in the bleeding, meatal stenosis, glans dehiscence, wound infection, UTI were statistically non-significant.

There was significant difference between the two groups in the occurrence of UF $(P=0.001)$, summarized in table 3 .

Table 3: Surgical complications for both groups

\begin{tabular}{|c|c|c|c|c|c|c|}
\hline & & & Group1 & Group2 & Total & P value \\
\hline \multirow{4}{*}{$\mathbf{U F}^{*}$} & \multirow{2}{*}{ No } & Count & 17 & 21 & 38 & \\
\hline & & $\%$ within Groups & $77.30 \%$ & $95.50 \%$ & $86.40 \%$ & \\
\hline & \multirow{2}{*}{ Yes } & Count & 5 & 1 & 6 & 0.001 \\
\hline & & $\%$ within Groups & $22.70 \%$ & $4.50 \%$ & $13.60 \%$ & \\
\hline \multirow{4}{*}{ Bleeding } & \multirow{2}{*}{ No } & Count & 20 & 19 & 39 & \\
\hline & & $\%$ within Groups & $90.90 \%$ & $86.40 \%$ & $88.60 \%$ & \\
\hline & \multirow{2}{*}{ Yes } & Count & 2 & 3 & 5 & $>0.05$ \\
\hline & & $\%$ within Groups & $9.10 \%$ & $13.60 \%$ & $11.40 \%$ & \\
\hline \multirow{4}{*}{$\begin{array}{l}\text { Meatal } \\
\text { stenosis }\end{array}$} & \multirow{2}{*}{ No } & Count & 20 & 19 & 39 & \\
\hline & & $\%$ within Groups & $90.90 \%$ & $86.40 \%$ & $88.60 \%$ & \\
\hline & \multirow{2}{*}{ Yes } & Count & 2 & 3 & 5 & $>0.05$ \\
\hline & & $\%$ within Groups & $9.10 \%$ & $13.60 \%$ & $11.40 \%$ & \\
\hline \multirow{4}{*}{$\begin{array}{c}\text { Glans } \\
\text { dehiscence }\end{array}$} & \multirow{2}{*}{ No } & Count & 21 & 21 & 42 & \\
\hline & & $\%$ within Groups & $95.50 \%$ & $95.50 \%$ & $95.50 \%$ & \\
\hline & \multirow{2}{*}{ Yes } & Count & 1 & 1 & 2 & $>0.05$ \\
\hline & & $\%$ within Groups & $4.50 \%$ & $4.50 \%$ & $4.50 \%$ & \\
\hline \multirow{4}{*}{$\begin{array}{l}\text { Wound } \\
\text { infection }\end{array}$} & \multirow{2}{*}{ No } & Count & 19 & 19 & 38 & \\
\hline & & $\%$ within Groups & $86.40 \%$ & $86.40 \%$ & $86.40 \%$ & \\
\hline & \multirow{2}{*}{ Yes } & Count & 3 & 3 & 6 & $>0.05$ \\
\hline & & $\%$ within Groups & $13.60 \%$ & $13.60 \%$ & $13.60 \%$ & \\
\hline \multirow{4}{*}{ UTI** } & \multirow{2}{*}{ No } & Count & 20 & 20 & 40 & \\
\hline & & $\%$ within Groups & $90.90 \%$ & $90.90 \%$ & $90.90 \%$ & \\
\hline & \multirow{2}{*}{ Yes } & Count & 2 & 2 & 4 & $>0.05$ \\
\hline & & $\%$ within Groups & $9.10 \%$ & $9.10 \%$ & $9.10 \%$ & \\
\hline
\end{tabular}

*Urethrocutaneous fistula **Urinary tract infection 


\section{Discussion}

The first TIP procedure for distal type hypospadias was described by Snodgrass ${ }^{7}$, which carried very good functional and cosmetic results. The success rate of this procedure depends on multiple facts that the urethral plate is a normal healthy tissue with muscle support and very good blood supply. The exact causes of fistula remain unknown. Shape of urethral plate, technical errors, local infection, poor tissue healing and distal obstruction may play a role in fistula formation ${ }^{8}$.

Retik et al, in 1994 was first described the use of dartos flap in TIP urethroplasty ${ }^{9}$. Dorsal dartos flap is well vascularised layer which use to cover the reconstructed neourthra. Ventral dartos flap, scrotal dartos flap and tunica vaginalis flap have been describing in special considerations as in redo operation or circumcised child ${ }^{10}$.

Kamal et al, 2005, the first one has reported a Double dartos flaps(DDF) to protect the neourethra, who reported that covering the neourethra with DDF was superior to single flap to prevent fistula development. Kamal et al, UF has developed in 2 patients in single layer dartos flap $(2 / 54)$ (3.7\%), and no fistula in 42 patients double dartos flaps $(0 / 42)(0 \%)^{11}$.

Balkan and Yildiz et al. UF has developed in 4 patients in single layer dartos flap (4/29) (13.8\%), and no fistula in 45 patients double dartos flaps $(0 / 45)(0 \%)^{12}$.

Savannelli et al find 5 cases of UF in single layer dartos flap (5/65) (7.7\%), and no fistula in double layer $(0 / 40)(0 \%){ }^{13}$.

Erol et al. in a prospective randomized study confirming that double symmetrical dartos flap to cover the neourethra decrease the fistula rate to $0 \%$ 14

In current study, UF has developed in 5 patients in group I (5/22) $(22.7 \%)$, and 1 case in group II $(1 / 22)(4.4 \%)$, which is statistically significant. UF was diagnosed after one month of operation in same child who was developed surgical site infection postoperatively treated by daily changing dressing and antibiotics covering for 2 weeks, we believe that the UF was happened as a complication of infection due to frequent changing of dressing and disrupting of skin stitches lead to weakening the second dartos layer, the fistula was treated by redo operation 6 months later.

Tubularized incisied plate urethroplasty was de- scribed a dorsal transverse island of dartos tissue used as flap ${ }^{15}$. Later on, Snodgrass transposed it ventrally in a buttonhole fashion to cover the neourethra 16 .

Djordevic et al, reported no fistula in 126 cases undergoing the TIP urethroplasty using additional coverage to ventral single layer flap by dorsal dartos flap is transposed to ventral side by button hole fashion ${ }^{17}$.

In current study, 2 layers of flap provide good protection from fistula because they have good blood supply and rich with nutrients, and if perforation or weakening occurs in one layer during dissection the second layer will cover the defect.

Nguyen and Sondgrass ${ }^{10}$, described that operative technique such as tubularization of neourethra too far distally plays an important role in future stenosis and fistula formation. In current study, the incised plate was tabularized over the Foley's catheter with a one-layer running subepithelial (5-0 vicryl suture), tubularization of the urethral plate was extended to the mid-glans only to obtain a slit like wide meatus, thus avoiding late meatal stenosis and fistula formation.

Meatal stenosis is a second most common complication after TIP urethroplasty. Lorenzo and Snodgrass ${ }^{18}$, suggested that regular meatal dilatation is not mandatory after TIP urethropalsty because this complication often develops as a result from a technical error such as not deeply incise the plate and tubularized the plate too far distally. Elbakry ${ }^{19}$ recommended that continuous urethral dilatation is very important for preventing meatal stenosis and UF by relieving adhesions between both sides of the incised plate.

In current study, Meatal stenosis was diagnosed in 2 patients $(9.1 \%)$ in group I and 3 patients $(13.6 \%)$ in group II, all 5 cases in both groups were treated conservatively by frequent dilatation.

Bleeding is another common complication of hypospadias repair, a significant hematoma is a dangerous which may cause infection and/or devascularization of flaps and graft, and failure of the surgical procedure. The most common causes of bleeding are inadequate hemostasis, trauma to the corpus cavernosum, bleeding from the resected corpus spongiosum for chordee correction. Bleeding can be avoided by several measures like applying a tourniquet at the base of penis, using 
bipolar electrocautery and Adrenaline solution (1: $100,000)$ is also helpful for hemostasis ${ }^{20}$.

In current study, s. Bleeding was happened in 5 cases $(11.4 \%)$ for both groups, 2 cases $(9.1 \%)$ in group I and 3 cases $(13.6 \%)$ in group II, all cases was treated conservatively with tight dressing except one case in group 2 was treated by surgical exploration.

Elbakry ${ }^{19}$ confirmed that the dartos flap should not be used because it hinders tension-free closure of the glans flaps and increases the risk of glans dehiscence.

In current study, glans dehiscence was seen in 1 case $(4.5 \%)$ for each group, the management for both groups was redo surgery.

Another compromising problem is wound dressing. There are a wide variety of dressings described in hypospadias surgery, from compressive dressing with cast immobilization, adhesive biomembrane dressing, to the complete absence of dressing ${ }^{21}$.

Savage et al ${ }^{22}$, supposed that the advantages of dressing are decreased swelling, wound disruption, and improved hemostasis. In contrast, there are also disadvantages of dressing after hypospadias repair, such as ischemia due to compression, infection, and pain during dressing removal.
In this study, we used a compressive dressing for (3-7) days to reduce the risk of bleeding and provide good hemostasis, as its in agreement with Shenoy NS et al study ${ }^{23}$, and El-Karamany TM et al study ${ }^{24}$.

\section{Conclusion}

- Tubularized incised plate urethroplasty remains most popular surgical intervention for treatment of distal hypospadias repair with good functional and cosmetic results, most of the complications were minor and treated conservatively.

- Neourethral covering with symmetrical well vascularized double dorsal dartos flaps represents a very good choice of UF prevention after TIP urethroplasty for distal hypospadias.

- Double darts flaps is easy to be harvested, safe procedure.

- Although the number of complicated patients are higher in group II than group I but there were statistically insignificant.

- We need more detailed studies with larger patients' sample to assess of DDF efficacy.

\section{References}

1. Schroder A, Stein R, Melchior S, Fisch M, Riedmiller H, Thuroff JW. Hypospadie. Urologe A 2006;45(Suppl 4):204-8.

2. Nuhoğlu B, Akgül KT, Ayyıldız A: Re: Mi- roslav L. Djordjevic, Sava V. Perovic, Zoran Slavkovic and Nenad Djakovic. Longitudi- nal dorsal dartos flap for prevention of fistula after a Snodgrass hypospadias procedure. Eur Urol 2006; 50:53-57.

3. Kamal BA: Double dartos flaps in tubularized incised hypospadias repair. Urology 2005; 66:1095-1098.

4. Holland A, Smith G. Effect of the depth and width of the urethral plate on tubularized incised plate urethroplasty. The Journal of urology. 2000;164(2):489-91.

5. Snodgrass WT: Tubularized incised plate (TIP) hypospadias repair. Urol Clin North Am 2002;29: 285-290.

6. Snodgrass WT, Bush N, Cost N. Tubularized incised plate hypospadias repair for distal hypospadias. Journal of pediatric urology. 2010;6(4):408-13.

7. Snodgrass WT: Tubularized incised plate urethroplasty for distal hypospadias. J Urol 1994; 151:464-465.

8. Erol A, Baskin LS, Li YW, Liu WH: Anatomical studies of the urethral plate: why preservation of the urethral plate is important in hypospadias repair. BJU Int 2000; 85:728- 734.

9. Retik AB, Mandell J, Bauer SB, Atala A: Meatal based hypospadias repair with the use of a dorsal subcutaneous flap to prevent urethrocutaneous fistula. J Urol 1994; 152:1229- 1231.

10. Nguyen MT, Snodgrass WT, Zaontz MR: Effect of urethral plate characteristics on tubularized incised plate urethroplasty. 2004; 171:1260-1262.

11. Kamal BA: Double dartos flaps in tubularized incised hypospadias repair. Urology 2005; 66:1095-1098.

12. Bakan V, Yildız A: Dorsal double-layer dartos flap for preventing fistulae formation in the Snodgrass technique. Urol Int 2007; 78: 241-244.

13 Savanelli A, Esposito C, Settimi A: A prospective randomized comparative study on the use of ventral subcutaneous flap to prevent fistulas in the Snodgrass repair for distal hypospadias. World J Urol 2007; 25:641-645. 
14. Erol A, Kayikci A, Memik O et al. Single vs double dartos interposition flaps in preventing urethrocutaneous fistula after tubularized incised plate urethroplasty in primary distal hypospadias: a prospective randomized study. Urol Int 2009; 83:354-358.

15. Snodgrass WT, Nguyen MT. Current technique of tubularized incised plate hypospadias repair. Urology 2002; 60:157162.

16. Snodgrass WT. Snodgrass technique for hypospadias repair. BJU Int 2005; 95:683-69.

17. Djordjevic ML, Perovic SV, Slavkovic Z, Djakovic N: Longitudinal dorsal dartos flap for prevention of fistula after Snodgrass hypospadias procedure. Eur Urol 2006; 50:53-57.

18. Lorenzo AJ, Snodgrass W: Regular dilatation is unnecessary after tubularized incised plate hypospadias repair. BJU Int 2002;89: 94-97.

19. Elbakry A: Tubularized-incised urethral plate urethroplasty: is regular dilatation necessary for success? BJU Int 1999; 84:683- 688.

20. Elbakry A, Shamaa M, Al-Atrash G. An axially vascularized meatal based flap for the repair of hypospadias. Br J Urol. $1998 ; 82: 698-703$.

21. El-Sherbiny M, Hafez A, Dawaba M, Shorrab A, Bazeed M. Comprehensive analysis of tubularized incised-plate urethroplasty in primary and re-operative hypospadias. BJU international. 2004;93(7):1057-61.

22. Van Savage JG, Palanca LG, Slaughenhoupt BLJTJou. A prospective randomized trial of dressings versus no dressings for hypospadias repair. 2000;164(3 Part 2):981-3.

23. Shenoy NS, Kumbhar VV, Shenoy YR, Sharma DB. Outcome of hypospadias repair-stentless versus stented repair. International Surgery Journal. 2016;3(4):2167-72.

24. El-Karamany TM, Al-Adl AM, Omar RG, Aal AMA, Eldakhakhny AS, Abdelbaki SAJU. A critical analysis of stented and unstented tubularized incised plate urethroplasty through a prospective randomized study and assessment of factors.

2017;107:202-8. 